with ugly protrusive profile, and Mongoloid features, the hair being arranged at the back of the head in a sort of "pig-tail." The Amaur or Amorites, on the other hand, are a handsome people, tall, and dolichocephalic, with large sub-aquiline noses, and a short pointed beard at the end of the chin. "The defenders of "the fort of Amaur" are represented as having been burnt a light pink-red by the action of the sun. Otherwise the skin is white or "sallow."

We learn, then, from the ancient monuments of Egypt that a portion of Palestine was occupied by a white race before its conquest by the Israelites. And they further inform us that this white race continued to exist in the country after the conquest. The physical characteristics of the captives taken by Shishak in the time of Rehoboam from the cities of Judah have Amorite and not Jewish features. There is nothing in common between them and the tribute-bearers of Jehu, who are depicted on the black obelisk from Nimroud, now in the British Museum, with faces of a most typically Jewish cast. In the tenth century before our era, consequently, the bulk of the population in the southern part of Judæa must have been of Amorite origin.

It is not wonderful, therefore, if we find traces of the same population still surviving in Palestine. There is no need of explaining their existence by a theory of their descent from the Crusaders. The survival of the ancient white race of Palestine is parallel to the survival of the ancient white race of Northern Africa, now generally known among French writers under the name of Kabyles. The Kabyles were at one time imagined to be the descendants of the Vandals, but we now know that they have inhabited the southern coast of the Mediterranean since the later Neolithic age. They are the Libyans of antiquity, represented on the Egyptian monuments, like the Amorites, with white skins, blue eyes, and dolichocephalic skulls, and similarly described by classical writers. They extended into Teneriffe and the Canary Islands, and their long-headed skulls have been disinterred from the dolmens of Northern Africa.

To the traveller who sees them for the first time the Kabyles offer a striking appearance. Their clear white skins, covered with freckles, their blue eyes and light hair, remind him of the so-called "Red Kelts" he has met with in an Irish village. They bear a high reputation for physical courage and love of independence, though at the same time they seem to be an orderly people. But they have two characteristics which they share with the white race of Northern Europe. They are mountaineers, the climate of the African plains being apparently too hot for them, and they are distinguished by their tall stature.

These were equally the characteristics of the Amorites of ancient Palestine. The Jews declared that their "height was like the height of the cedar," the Semitic tribes by the side of them seeming to be but "grasshoppers," and the iron couch of Og, the Amorite king of Bashan, preserved at Rabbath, afterwards the capital of Ammon, excited the wonder of later generations on account of its size.

The Amorites also occupied the whole of the mountainous district of Syria and Palestine from the neighbourhood of Kadesh in the north to the desert southward of Judah, and on the eastern side of the Jordan they founded the two kingdoms of Bashan and Heshbon. In the mountains of Moab and Seir they formed the aboriginal population, partially dispossessed by the Semitic tribes of Moab, Ammon, and Edom, and the name of Horite under which they went in Edom is best explained as meaning "white," in contradistinction to the Semitic Edomite or "red-man." A passage in the Pentateuch (Numbers xiii. 29) expressly states that along with the Hittites and Jebusites they inhabited the mountainous region, while the Canaanites dwelt on the coast and the valley of the Jordan. That Jebusite simply means a cross between Hittite and Amorite is clear from the statement of Ezekiel (xvi. 3, 4, 5) that Jerusalem, whose old name of Jebus gave rise to that of Jebusite, was born of a Hittite mother and an Amorite father. The Egyptian monuments bear witness to the same "interlocking" of Hittite and Amorite.

There is yet a third characteristic which has been ascribed to the white race of Northern Europe. It has been brought into close connection with the dolmens which cover so large a part of its territory. Faidherbe and others have traced a continuous line of dolmens of similar construction along the northern coast of Africa, through Spain, Portugal, and France, into the British Isles. No one, indeed, who has examined the famous dolmens of Roknia, in Algeria, can fail to be struck by their resemblance to the sepulchral cromlechs of our own country. If they are really due to the genius and influence of a single race, it would seem that the race moved from north to south, since the objects found in the dolmens of the south of France betray a more advanced stage of culture than those found in the north.

The chief objection hitherto raised against ascribing these dolmens to the white race with whom they are associated has been that similar megalithic monuments exist in Palestine. Over 700 have been discovered in Moab on the eastern side of the Jordan. Major Conder has drawn attention to others in the basaltic region in the neirrhbourhood of the ancient Dan, and though none have as yet been observed in Judah, this is probably due to the fact that the attention of travellers has not been called to them. I have myself come across a fine specimen on a hill to the south of Jenîn which had been overlooked by the Palestine Survey, and that megalithic structures once existed in Judah is evident from the occurrence in the Old Testament of names like Gilgal or "Stone-circle," and Ai or "cairn" (Joshua viii. 29). It will be noticed that they are especially plentiful on the eastern side of the Jordan, where the two chief Amorite kingdoms once flourished. Just as the dolmens of Northern Africa were the burial-places of the ancestors of the Kabyles, so tradition affirmed that the Amorite king of $\mathrm{Ai}$ had been buried beneath a cairn of stones.

The discovery that the Amorites of Palestine were racially allied to the ancient Libyans opens up ethnological and archæological questions of considerable interest. These cannot be touched upon here, but must be reserved for a future occasion. It is sufficient for the present to have drawn attention to a new and curious ethnological fact.

A H. SAYCE.

\section{ENGINEERING SCHOOLS.}

$A \mathrm{~T}$ a time when so much is being said about the need for technical education, especially in engineering, the following letter will be read with interest :- -

\section{Engineering Sihool, Trinity College, Dublin, June 1888 .}

DEAR LORD Ashbourne,-As you have requested me to draw up a statement of the claims of engineering schools to be recognized by the Civil Service Commissioners as affording part at least of the technical training required of candidates for engineering Civil Service appointments, I send you the following account.

Allow me, in the first place, to state that I am not advocating the claims of our Engineering School here as in any way distinct from that of many other excellent engineering schools that exist. For instance, the Indian Government is so fully convinced of the absolute neressity for a proper technical school training for engineers that it requires all candidates for Indian engineering appoint- 
ments to go through Cooper's Hill Engineering School ; and yet the Home Civil Service do not in any way even recognize the very same technical training given to other students who stay at home as of any value at all.

The instruction given in engineering schools is of two kinds :- -

I. Lectures and demonstrations in mathematics, mechanics, physics, chemistry, geology, \&c.; and in the theory and practice of engineering, surveying, \&c., \&c.

II. Practical training-

(a) Practical work in laboratories and workshops in mechanics, machines, physics, chemistry, and field-work in geology.

(b) Drawing and office work, including designing, making out specifications, taking out quantitics, \&c., \&c.

(c) Practical surveying, and all manner of field work.

(d) Inspection of works in progress.

It will be observed what a large and important part of the training given in a school cannot be obtained in an office at all. All the instruction in mathematics, mechanics, physics, chemistry, geology, \&c., and in the theory of engineering, and all the important practical laboratory training in these subjects, can only be obtained in a school; and unless an engineer has been properly and practically taught these things before entering on his profession, it is almost certain that he will never learn them. In the other more especially engineering parts of the course there are sevcral great advantages in the school course over the office course. In the school, in the first place, the student is under the constant instruction of teachers whose time is devoted to instructing the student, and explaining to him the principles upon which his work depends; and, in the second place, the course of instruction covers as wide a range of subjects as is consistent with teaching each properly. In the office, in the first place, the apprentice has to pick up what instruction he can, and is generally content with a rule-of-thumb knowledge, that may desert him at any really critical juncture; and, in the second place, in any one office the work is yearly becoming more specialized, so that an apprentice will have experience of only a small range of subjects, and, not being acquainted with the theory of even these, will be incompetent to engage in other work.

There are, of course, certain things, such as facility in numerical calculation, and perhaps in the use of fieldinstruments, acquaintance with the details of specifications in a particular class of work, familiarity with prices at a particular time, and an opportunity of seeings designs carried into execution, which cannot be as well obtained in school as on works. The object of a school being to teach, and of works being to pay, neither can completely supply the place of the other. As a course of technical training for a young engineer, the school course is out of all proportion the more important. What can be learnt from the office course will certainly be acquired, while what can be learnt from the school course will hardly ever be acquired, unless learnt before beginuing the practice of his profession. In this age of technical education it is practically certain that in a few years no engineer will be recognized as such unless he has had a proper technical school education, just as in the medical profession it has long ago been recognized that, without a proper medical school education, it is impossible for a doctor to learn the many sciences upon which the successful practice of his profession necessarily depends.

Eminent engineers who have had experience of students taught in engincering schools hold opinions similar to those here enunciated. Our late Professor of Engineering, Mr. Crawford, whose engineering experience is woridwide, is of this opinion. Mr. Bindon B. Stoney, Engineer to the Dublin Port and Docks Board, is of the same opinion. Both these have had experience of schooltrained students, and think that the proper course for a young engineer to pursue is to go through a course of instruction in a properly-equipped school, and then to go for a year on works. They consider that a year on works is required to complete the education of an cngineer, and they think that a short time on works is quite sufficient for a student who has already gone through an engineering school. Mr. Stoney, for instance, takes students who have been through an engineering school as apprentices for one year, although he will not take untrained apprentices for so short a term.

Foreign Governments in general require all who profess to practise as engineers to go through a proper technical school training, and it is a serious difficulty in the way of English engineers who endeavour to obtain employment on the Continent that, even though they may have been trained in an excellent school, yet this is not recognized by foreign Governments, because our engineering schools are in no way recognized by our own Government.

The Civil Service Commissioners should endeavour to encourage the proper scientific training of the engineers they receive into the public service, and they can do so by recognizing the years spent in an engineering school as equivalent to the same number of years of the technical training that is now required. In the more important appointments, which at present require five years'technical training, the candidate would have to supplement his school course by an office course of at least two years; and this, in the opinion of eminent engineers, as quoted above, would be amply sufficient. In the case of the less important appointments, the school training is probably much better than what satisfies the Commissioners at present ; but if it is thought that the special qualifications of an office-trained apprentice are essential, they can be easily secured by requiring in every case at least one year's office experience.

The Civil Service Commissioners should, before recognizing any engineering school as giving the instruction qualifying a candidate to compete for an appointment, inspect the school, and see that it is properly equipped, and has the means and teachers required to teach what it professes. For instance, in some schools there is no special instruction in architecture, and this special teaching should be required of any school that was recosnized as qualifying candidates for specially architectural appointments. Similarly, in the case of mechanical engineering, some schools have not the means of teaching it properly, and these schools should not be recognized as qualifying candidates for specially mechanical engineering appointments. A school that teaches civil engineering should be recognized as such, and only as such; and similarly, one that only teaches mechanical engineering should be recognized only as such. In the case of medical appointments, the State recognition of schools is already fully carried out, so that there can be no insuperable difficulty in doing the same in the case of the engineering appointments.

If the Civil Service Commissioners require further information as to the instruction imparted in engineering schools, it would be well for them to inspect University College, London, the City and Guilds of London Institute, and Cooper's Hill, all of which are easy of access from London; and if they require further information they had better appoint some competent Committee to inspect and report to them generally as to the training given in engineering schools, and as to whether they give a technical training that the Civil Service Commissioners would recognize as equivalent to some years spent in an office; and, if not, how the schools should modify their courses so as to give this instruction. Statements as to the nature and value of instruction made by those interested in it and responsible for it are not so valuable as independent testimony.

In conclusion, I would earnestly press upon the Civil Service Commissioners the very great desirability of their encouraging scientifically-trained candidates to apply for 
appointments in the Civil Service. The application of scientific principles to engineering is the special feature of our age, and instruction in these principles, and practical training in their application, should be part of the training of every engineer; and this can only be acquired in a properly-equipped school. A want of familiarity with details will surely be remedied, but a want of scientific knowledge will be a lasting cause of danger to the public.

Yours very truly,

GEORGE FRANCIS FitzGerald.

\section{THE GAPE WORM OF FOWISS (SYNGAMUS TRACHEALIS).}

I $N$ the Bulletin of the Buffalo Society of Natura Sciences, vol. v. No. 2, 1886-7, is a paper by Dr. H. D. Walker, which does not appear to bave been noticed in this country, on "The Gape Worm of Fowls (Syngamus trachealis)." The writer claims to have discovered that the common earthworm (Lumbricus terrestris) is the intermediate host of this well-known parasite, and to have observed it in all stages of its development. He further suggests the use of common salt on infected poultry runs to secure the extermination of these noxious pests by destroying the worms which harbour and distribute them.

The series of experiments by which he has arrived at his conclusions are interesting, and afford strong presumtive evidence of their correctness. The earthworms were carefully dissected and examined, the embryonic form of Syngamus being found in them, "differing but slightly in structure, so far as can be discovered from the embryo which has passed through one moult after the egg has hatched in water."

The question may be asked: Why should it differ at all if it is the same? It may be suggested that earthworms are themselves subject to various intestinal parasites and that the embryonic forms of many species and even genera are scarcely distinguishable from each other but with a view to obtaining corroborative evidence $\mathrm{Dr}$. Walker fed some chickens with worms obtained from a place where Syngamus had not been noticed. These chickens did not develop the gapes. An examination of worms from this spot showed them to be free from embryos such as were found in others. The double observation certainly points to the probability that in the first instance the embryo of Syngamus had been rightly recognized.

Embryos were also found in the œsophagus and in the lungs of birds to which earthworms taken from an infected locality, but carefully washed and cleansed externally, had been given.

The only link apparently wanting to complete the chain of evidence is to determine the manner in which the parasite (if it be truly the embryo of Syngamus) makes its way into the intestinal canal of the earthworm.

Dr. Walker concludes that it is taken in with its food. His evidence upon this point is chiefly negative. Eggs of Syngamus were placed on damp earth in a dish to which living earthworms were added a fortnight later. After ten days chickens were fed with these worms, but were not attacked. This experiment would have been more complete and perhaps conclusive if the worms had been supplied at the same time with vegetable food. Unless the worms were fed, the only means of entry for the embryos of the parasite must have been by boring through the outer integument of their bodies, which is not suggested.

Dr. Walker notices and examines somewhat critically a paper by Dr. Pierre Mégnin, published under the auspices of the Entornological Society of London in 1883 , in which the author, after a minute inquiry into the history, habits, and development of Syngamus trachealis, came to the conclusion that the epidemic of gapes is spread, first by "food or drink which has become infested with eggs or embryos ; secondly, (by) the diseased birds themselves, which are constantly disseminating the eggs of the parasite; and therefore all other living agents, perfect insects, larvæ, or mollusks (for example, the larvæ of ants, which are the habitual food of young pheasants, have been suspected, with some appearance of reason' may be acquitted of any share in spreading the disease." The American author disputes these conclusions. Admitting that the eggs will hatch in water, and that the embryos may be taken in by birds drinking infected water, he finds no instance, after repeated experiments, in which eggs swallowed by a bird have produced the disease, and although he thinks that exceptional cases might occur, he concludes that the instrumentality of the intermediate host is not ordinarily dispensed with. This is the only material point in which Walker differs from Mégnin, and there is nothing in Walker's discoveries to impair the accuracy of Mégnin's observations, so far as they go. Dr. Walker's observations on the structure and development of the parasite from the egg through its embryonic stages agree substantially in all other respects with those of Dr. Mégnin, except that he believes "the egg of Syngamus within the perfect worm just arrived at maturity does not contain a developed embryo," whereas Mégnin found "embryos quite perfect and living in eggs not yct freed from the decomposing bodies of female Syngami attached to the tracheal mucous of pheasants that had died of gapes."

The discovery of the distribution of these parasites through the instrumentality of earthworms, which are undoubtedly a favourite food of all young game birds, as well as of domestic fowls, is especially interesting to game preservers, and the theory is strongly supported by their experience.

First, if, as Dr. Mégnin believed, the eggs could be hatched only in water, a gamekeeper could have counted upon reducing to a minimum the risk to his artificiallyreared birds by depriving them of water and feeding them upon food carefully moistened with pure spring water only, or more conveniently, upon water that had been first boiled. Many have followed this rule habitually and with good results, but certainly without securing any immunity from occasional outbreaks of the "gapes disease." Secondly, all who have had any experience in rearing pheasants or partridges, or have observed the growth and health of broods of the young of these birds in a wild state, must have noticed that very dry summers are much more favourable to the maturing of full broods and coveys than those in which a greater degree of moisture prevails, but if after very dry weather copious showers or very heavy dews moisten the surface of the ground when the birds have not yet attained their full growth, an outbreak of gapes is almost certain to follow, and is very rapid in its effects. So long as the ground is hard and dry earthworms do not come to the surface, but whenever it becomes sufficiently moistened to permit them to throw up their casts and to reach the surface, all species of birds of which they form a natural or favourite food are eager to seek and to devour them. The birds named by I)r. Walker as those in which Syngamus has been found are, with the single exception of the swift, all worm-eating birds. He does not mention on what authority the swift is included in the list, but it is difficult to understand, if water is to be regarded as the only medium of conveyance for this parasitic disease, why many other birds should not also have been found to be affected by it. We believe Dr. Walker's discovery has been received in America with some incredulity, but apart from the careful observations and experiments on which he relies, the accuracy of which there seems to be 